\title{
Article \\ Characterization of Kazachstania slooffiae, a Proposed Commensal in the Porcine Gut
}

\author{
Katie Lynn Summers*(D), Juli Foster Frey and Ann M. Arfken \\ Animal Biosciences and Biotechnology Laboratory, Beltsville Agricultural Research Center, ARS, USDA, \\ Beltsville, MD 20705, USA; juli.frey@usda.gov (J.F.F.); annma31415@aol.com (A.M.A.) \\ * Correspondence: katie.summers@usda.gov; Tel.: +1-(301)-504-8760
}

check for updates

Citation: Summers, K.L.;

Foster Frey, J.; Arfken, A.M. Characterization of Kazachstania slooffiae, a Proposed Commensal in the Porcine Gut. J. Fungi 2021, 7, 146. https://doi.org/10.3390/ jof7020146

Academic Editor: David S. Perlin

Received: 29 January 2021

Accepted: 16 February 2021

Published: 17 February 2021

Publisher's Note: MDPI stays neutral with regard to jurisdictional claims in published maps and institutional affiliations.

Copyright: (c) 2021 by the authors. Licensee MDPI, Basel, Switzerland. This article is an open access article distributed under the terms and conditions of the Creative Commons Attribution (CC BY) license (https:// creativecommons.org/licenses/by/ $4.0 /)$.

\begin{abstract}
Kazachstania slooffiae is a fungus commonly isolated from the gastrointestinal tract and feces of post-weaning pigs. Studies have implicated its ability to positively alter piglet gut health through potential symbioses with beneficial bacteria, including Lactobacillus and Prevotella, in providing amino acids as an energy source for microbial and piglet growth, and it has been found to be positively correlated with short-chain fatty acids in the piglet gut. However, basic mycological information remains limited, hampering in vitro studies. In this study, we characterized the growth parameters, biofilm formation ability, susceptibility to antimicrobials, and genetic relatedness of $K$. slooffiae to other fungal isolates. Optimal fungal growth conditions were determined, no antifungal resistance was found against multiple classes of antifungal drugs (azoles, echinocandins, polyenes, or pyrimidine analogues), and dimorphic growth was observed. K. slooffiae produced biofilms that became more complex in the presence of Lactobacillus acidophilus supernatant, suggesting positive interactions with this bacterium in the gut, while Enterococcus faecalis supernatant decreased density, suggesting an antagonistic interaction. This study characterizes the in vitro growth conditions that are optimal for further studies of $K$. slooffiae, which is an important step in defining the role and interactions of K. slooffiae in the porcine gut environment.
\end{abstract}

Keywords: Kazachstania slooffiae; mycobiome; microbiome; pig; porcine; swine; biofilms; Lactobacillus; Enterococcus

\section{Introduction}

Weaning is a critical phase in piglet life and is associated with increased stress, reduced growth performance, and predisposition to opportunistic infections such as post-weaning diarrhea [1-3]. The ability to identify potential growth promotants in agricultural animals is critical to reduce infections seen during weaning, promote pork production, and reduce farmer loss. Significant alterations in the composition of the bacteriome and mycobiome have been documented during the weaning transition, but specific interactions between the microbiome and the immune system, that result in altered growth, remain to be determined. The microbiome is an integral player in animal health and recently, members of the rare biosphere [4] have been recognized as being critical in altering bacterial-fungal-host interactions, and therefore, animal health and growth. Members of the mycobiome can alter host health, and disruption of members of the mycobiome can result in disease [5-12]. Furthermore, commensal fungi can alter host immunity during normal health as well as modify the severity of some diseases [13-18].

One important member of the rare biosphere in swine is the fungus Kazachstania slooffiae. K. slooffiae has been found to be the predominant post-weaning fungi in the gastrointestinal (GI) tract and feces of piglets. This fungus persists in adult pigs across geography and may play a role in providing nutritional benefits to pigs [19-26]. K. slooffiae is a yeast that is closely related to species such as Candida (Kazachstania) pintolopesii and Candida (Kazachstania) bovina, and it is a member of the Kazachstania (Arxiozyma) telluris species complex [27]. Kurtzman et al. utilized strains originally isolated from horse and porcine ceca and described $K$. slooffiae as vegetative 
with spherical to ellipsoidal cells and multilateral budding, resulting in lobate colony growth and lacking true hyphae. In swine, positive inferred interactions have been found between K. slooffiae and beneficial gut bacteria including Prevotella and Lactobacillus [19,20]. Despite these previous studies, little is known about this fungus and its role in modulating the microbial milieu in the gut, and thus, piglet health, growth, and disease resistance.

In this study, we aimed to further document the growth parameters of piglet-derived K. slooffiae under different in vitro nutrient conditions, assess microscopic growth characteristics and antimicrobial resistance, characterize related strains based on available sequencing data, and utilize biofilm assays to elucidate the ability of $K$. slooffiae to grow as a biofilm in the presence of different potential bacterial antagonists and synergists. This study lays the groundwork for future studies to assess the role of $K$. slooffiae in altering piglet health through fungal-bacterial interactions during the critical weaning transition.

\section{Materials and Methods}

Culture isolation and sequencing of $K$. slooffiae. Fecal samples were collected from post-weaning piglets (age 22-28 days) using sterile weigh basins and then transferred to sterile $50 \mathrm{~mL}$ conical tubes. Samples were weighed, normalized to $0.2 \mathrm{~g}$ of feces, $2 \mathrm{~mL}$ of sterile 1X PBS was added, and samples were homogenized in a biological safety cabinet. Post-homogenization, samples were serially diluted and plated in triplicate on Sabouraud Dextrose Agar (SDA) and Yeast Potato Dextrose Agar (YPD) (BD Difco, Franklin Lakes, NJ, USA). Both agar types were supplemented with $0.1 \mathrm{mg} / \mathrm{mL}$ cefoperazone (cef), a broadspectrum cephalosporin, to reduce bacterial growth on plates (Sigma-Aldrich, St. Louis, MO, USA). Agar plates were incubated under different temperature conditions $\left(37^{\circ} \mathrm{C}\right.$, $20{ }^{\circ} \mathrm{C}$ ) and with and without $5 \% \mathrm{CO}_{2}$ supplementation. Colonies that grew were Sanger sequenced utilizing ITS-2 (Internal Transcribed Spacer region 2) primers for identification (ITS3: 5'-GCATCGATGAAGAACGCAGC; ITS4: 5'-TCCTCCGCTTATTGATATGC) [28]. Sequencing results determined that the predominant fungal species was Kazachstania slooffiae, which was previously isolated in pigs $[19,21,24-26]$.

For genome sequencing, one colony from a YPD + cef agar plate of sequence-confirmed K. slooffiae was used to inoculate $4 \mathrm{~mL}$ YPD + cef liquid media. The culture was incubated at $37^{\circ} \mathrm{C}, 200 \mathrm{rpm}$, with culture volume gradually increased over the next 2 days by adding fresh YPD + cef to a total of $120 \mathrm{~mL}$. On day 3 of incubation, fungal cells were collected in 4 individual $30 \mathrm{~mL}$ aliquots by centrifuging at $100 \times g$ for $5 \mathrm{~min}$. Supernatants were removed, and pellet dry weights were weighed (0.60-0.76 g). Each pellet was homogenized $3 x$ in liquid $\mathrm{N}_{2}$ with a Tissue Homogenizer (Omni International, Kennesaw, GA, USA) and kept on dry ice until genomic DNA was isolated using the DNeasy Plant Maxi Kit (Qiagen, Hilden, Germany). DNA was quantified with the Qubit Flex (Invitrogen, Carlsbad, CA, USA) and visualized with a $0.7 \%$ agarose gel to check for high-quality, high molecular weight DNA. Whole-genome sequencing of the K. slooffiae isolate was performed on the PacBio Sequel II 18M SMRT Cell platform. The resulting long reads were quality checked, and a draft genome was assembled with FALCON ver.0.5 [29] at the University of Maryland Genomics Resource Center.

Antifungal susceptibility. Fungal cultures were started from 1 colony in $5 \mathrm{~mL}$ of $\mathrm{YPD}+$ cef or SDB + cef and grown at $37^{\circ} \mathrm{C}, 5 \% \mathrm{CO}_{2}$ for $24 \mathrm{~h}$. Then, these cultures were inoculated into $20 \mathrm{~mL}$ of matching media broth for a total of $25 \mathrm{~mL}$ of broth culture. These were allowed to grow for an additional $24 \mathrm{~h}$. Upon growth density, a sterile cotton tip swab was dipped into the broth in a biological safety cabinet and rubbed across an agar plate. This swab was repeated 2 more times, and the culture was allowed to air dry in the BSC. Upon drying, the antifungal or antibiotic of interest was added to the middle of the agar plate, and plates were incubated at $37{ }^{\circ} \mathrm{C}, 5 \% \mathrm{CO}_{2}$ and results were read at 24, 48, and $72 \mathrm{~h}$. When possible, Minimum Inhibitory Concentration (MIC) Test Strips (MTS) were used to assess MIC (flucytosine, itraconazole, caspofungin, voriconazole) (Liofilchem, Roseto degli Abruzzi, Italy). Susceptibility or resistance was based on the ability of the antimicrobial to create a zone of fungal growth clearance. 
Growth curve. Five $5 \mathrm{~mL}$ starter cultures of YPD $+0.1 \mathrm{mg} / \mathrm{mL}$ cef were inoculated with a single colony each of $K$. slooffiae. After $39 \mathrm{~h}$ of incubation at $37^{\circ} \mathrm{C}$, shaking at $200 \mathrm{rpm}$, twenty $20 \mathrm{~mL}$ cultures were created from $1 \mathrm{~mL}$ of starter culture $+19 \mathrm{~mL}$ YPD + cef. Samples were briefly vortexed before removing a $200 \mu \mathrm{L}$ aliquot and $\mathrm{OD}_{600}$ readings were taken every two hours, from $T_{0}$ to $20 \mathrm{~h}$. Serial plating at $T_{0}$ determined the average starting inoculum to be $4.5 \times 10^{5} \mathrm{CFU}$ (colony forming units) $/ \mathrm{mL}$. C. albicans $\mathrm{CHN} 1$ growth curves were performed similarly. However, due to the denser and more rapid growth of this species, $0.5 \mathrm{~mL}$ of starter culture $+19.5 \mathrm{~mL}$ YPD + cef were started. $\mathrm{OD}_{600}$ readings were taken every two hours from $T_{0}$ to $11 \mathrm{~h}$. Serial plating at $\mathrm{T}_{0}$ determined the average starting inoculum to be $3.5 \times 10^{6} \mathrm{CFU} / \mathrm{mL}$. CFU counts for the growth curve were determined through serial dilutions on YPD + cef agar plates and read after 24-36 h $(n=3$ for each fungus at each time point).

Amplicon size determination. Fungal colonies were grown for K. slooffiae and C. albicans, as described above, and $5 \mathrm{~mL}$ cultures were inoculated with a single colony. After $24 \mathrm{~h}$ of growth, whole DNA was isolated using the DNeasy PowerSoil Pro Kit (Qiagen). PCR amplification was performed on the DNA isolated with 18S, ITS-1, or ITS2 primers $(0.03 \mu \mathrm{M})$ (Table 1$)$ using the following parameters: $95^{\circ} \mathrm{C}$ or $3 \mathrm{~min}$; followed by 35 cycles of $98{ }^{\circ} \mathrm{C}$ for $30 \mathrm{~s}, 60^{\circ} \mathrm{C}$ for $3 \mathrm{~min}, 72{ }^{\circ} \mathrm{C}$ for $30 \mathrm{~s}$, and a final extension at $72{ }^{\circ} \mathrm{C}$ for $5 \mathrm{~min}$. Samples were run on an Agilent Bioanalyzer 2100 and confirmed on a $2 \%$ ethidium bromide gel (data not shown).

Table 1. Fungal-specific primers.

\begin{tabular}{cccc}
\hline Primer Target & Primer Name & $\begin{array}{c}\text { Primer Sequence (5' } \\
->\mathbf{3}^{\prime} \mathbf{)}\end{array}$ & Citation \\
\hline ITS-1 Forward & ITS1 & CTTGGTCATTTAGAG & {$[30]$} \\
\hline ITS-1 Reverse & ITS2 & GCTGCGTTCTTCATCGATGC & {$[30]$} \\
\hline ITS-2 Forward & ITS3 & GCATCGATGAAGAAC & {$[28]$} \\
\hline ITS-2 Reverse & ITS4 & TCCTCCGCTTATTGATATGC & {$[28]$} \\
\hline 18S Forward & FF290F & CGATAACGAACGAG & {$[31]$} \\
\hline 18S Reverse & FR-1R & ANCCATTCAATCGGTANT & {$[31]$} \\
\hline
\end{tabular}

Microscopy. Fungal cultures were grown as described above, and wet mounts were captured on an Olympus IX73 microscope (Olympus America, Inc., Center Valley, PA, USA) equipped with a Hamamatsu ORCA-R2 digital CCD camera (Hamamtsu Corporation, Bridgewater, NJ, USA) and measured using the Olympus CellSense Dimension (ver.2.1) software.

Phylogenetic tree. The full ITS gene region (ITS1-5.8S-ITS2) in the assembled K. slooffiae isolate draft genome was extracted using ITSx version 1.1.2 [32]. Additional Kazachstania sp. ITS gene region sequences were downloaded from the National Center for Biotechnology Information (NCBI) RefSeq database [33]. Remaining SSU and LSU regions in the downloaded ITS gene sequences were identified and removed using ITSx version 1.1.2. Combined Kazachstania ITS gene region sequences from RefSeq and this study were aligned with MUSCLE [34]. Phylogenetic trees were constructed using maximum likelihood (ML) with 1000 bootstrap replicates under the Tamura-Nei model [35]. Both alignments and tree construction were conducted in MEGA version X [36]. Naumovozyma (Saccharomyces) castellii, a closely related genus, was selected as an outgroup.

Biofilms. A single colony of $K$. slooffiae was inoculated into $5 \mathrm{~mL}$ of broth media of interest and grown at $37^{\circ} \mathrm{C}$ for $24 \mathrm{~h}$. Then, this culture was inoculated into $20 \mathrm{~mL}$ of broth media and grown for another $24 \mathrm{~h}$. Then, $200 \mu \mathrm{L}$ of $K$. slooffiae was plated into Falcon sterile, tissue culture grade 96-well, flat-bottom plates (Corning, Glendale, AZ), treatments of interest were added, plates were wrapped with parafilm to prevent evaporation, and they were grown without shaking at $37^{\circ} \mathrm{C}, 5 \% \mathrm{CO}_{2}$ for $72 \mathrm{~h}$. For each experiment, the culture of $\mathrm{K}$. slooffiae was replica plated onto the corresponding agar type to assess the fungal burden in each well and incubated at $37{ }^{\circ} \mathrm{C} 5 \% \mathrm{CO}_{2}$ for $48 \mathrm{~h}$ prior to reading. As previously published, biofilms were stained and assessed for optical density [37,38]. 
Briefly, at $72 \mathrm{~h}$, the supernatant from the biofilm plates was gently removed and biofilms were air-dried for $45 \mathrm{~min}$. Following air-drying, $200 \mu \mathrm{L}$ of $4 \%$ paraformaldehyde was added and plates were incubated at room temperature for $45 \mathrm{~min}$. Following incubation, the paraformaldehyde was removed, and plates were gently washed $4 \mathrm{x}$ with $350 \mu \mathrm{L}$ of sterile 1X phosphate buffered saline (PBS). Then, $110 \mu \mathrm{L}$ of $4 \%$ aqueous crystal violet was added to each well and incubated for $45 \mathrm{~min}$ prior to washing $3 \mathrm{x}$ with $350 \mu \mathrm{L}$ sterile water. Next, $200 \mu \mathrm{L}$ of $95 \%$ ethanol was added to each well to destain the biofilms for $45 \mathrm{~min}$. Finally, $100 \mu \mathrm{L}$ was transferred from each well into a fresh 96-well plate and read at $595 \mathrm{~nm}$ on a SpectraMax 340 plate reader (Molecular Devices, San Jose, CA, USA). Supernatants from bacterial isolates were used to test alterations on K. slooffiae biofilm density: Enterococcus faecalis ATCC BAA-2128 (piglet feces isolate), Lactobacillus acidophilus ATCC 53671 (swine intestinal isolate), and Lactobacillus fermentum ATCC 23271 (human intestinal isolate). Bacterial cultures were grown from glycerol stock stored at $-80^{\circ} \mathrm{C}$ by inoculating into $5 \mathrm{~mL}$ of De Man, Rogosa, Sharpe broth (MRS) and incubated at $37^{\circ} \mathrm{C}$ for $24 \mathrm{~h}$ without shaking. Following bacterial growth, cultures were spun down for $5 \mathrm{~min}$ at $211 \times g$, supernatant was removed, and $50 \mu \mathrm{L}$ of supernatant was added to each biofilm well. Replica plating of bacterial cultures were performed on MRS agar plates to confirm bacterial numbers.

Statistics. Statistical analyses were performed in GraphPad Prism version 8.4.3. (GraphPad Software, San Diego, CA, USA). The statistical significances between biofilm growth were determined using a one-way ANOVA with a Tukey post-test. Values of $p<0.05$ were considered significant.

\section{Results}

Growth of K. slooffiae. K. slooffiae was isolated from fecal samples directly sampled from piglets in the week post-weaning (age 22-28 days) and grown as described in the methods. Confirmed isolates were grown for $24-72 \mathrm{~h}$ on Yeast Potato Dextrose (YPD) and Sabouraud Dextrose (SDA) nutrient agars (Figure 1). Colonies were shiny, creamcolored with lobate margins. While colonies grown on YPD displayed a concave elevation (Figure 1A,B), colonies grown on SDA displayed a flat elevation (Figure 1C,D). YPD broth culture grown at $37^{\circ} \mathrm{C}$ without shaking both displayed sediment growth (Figure 1E,F). Sediment growth was also seen in YPD broth at $37^{\circ} \mathrm{C}$ with shaking at $200 \mathrm{rpm}$ and in cultures grown in SDB with or without shaking (not shown). As seen in previous literature, K. slooffiae grows as a spherical, yeast, or as pseudohyphae (Figure 2), and budding yeasts were seen (Figure 2B). Pseudohyphae were scarcely differentiated, and no ascopores were seen in our experiments.

To assess the growth rate of $K$. slooffiae in comparison to another gut fungi, we performed growth curves for K. slooffiae and Candida albicans CHN1 (human gut isolate). Cultures were followed for $26 \mathrm{~h}$ or longer, and growth for $C$. albicans $\mathrm{CHN} 1$ outgrew K. slooffiae regardless of nutrient broth. Exponential growth for K. slooffiae was seen between 1 and $8 \mathrm{~h}$ with a plateau at $\mathrm{OD}_{595 \mathrm{~nm}} 0.843$ (Figure 3). Colony counts were assessed throughout the time course, and at $4 \mathrm{~h}$ of growth, K. slooffiae had a density of $9.50 \times 10^{6} \mathrm{CFU}$, which appeared to plateau through $26 \mathrm{~h}$ of growth, where the CFU remained similar at $9.58 \times 10^{6}$. C. albicans $\mathrm{CHN} 1$ cultures demonstrated faster growth with $4.11 \times 10^{7} \mathrm{CFU}$ by $4 \mathrm{~h}$, plateaued at $8 \mathrm{~h}$ with $1.91 \times 10^{8} \mathrm{CFU}$, and $1.61 \times 10^{8} \mathrm{CFU}$ at $26 \mathrm{~h}$ of growth. K. slooffiae was assessed for antimicrobial resistance to four classes of antifungal drugs and two antibiotics as controls. K. slooffiae was grown on YPD agar and SDA, and growth inhibition was assessed through Minimum Inhibitory Concentrations (MIC). No difference in antimicrobial susceptibility was seen between the two growth conditions (SDA not shown), and no resistance was seen for azoles (fluconazole, voriconazole, itraconazole), echinocandins (caspofungin), polyenes (amphotericin B), pyrimidine analogues (flucytosine) or antibiotics (ampicillin (beta-lactam), cefoperazone (cephalosporin)) (Table 2). 
A.

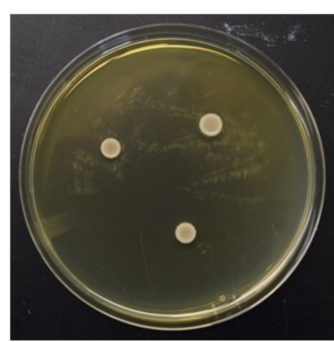

B.

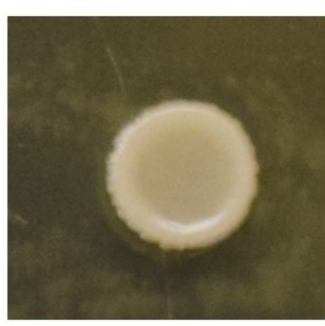

C.

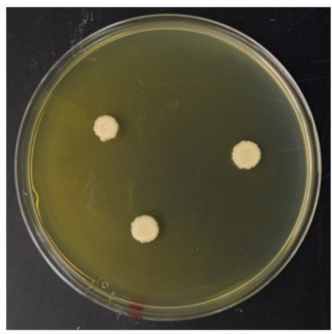

D.

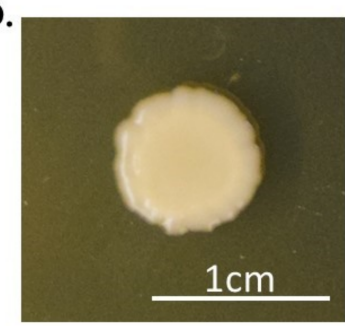

E.

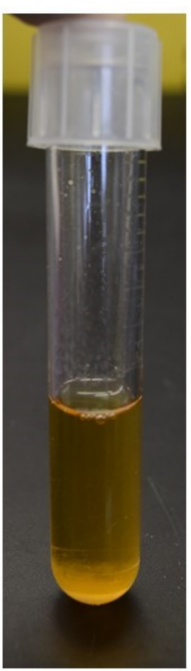

F.

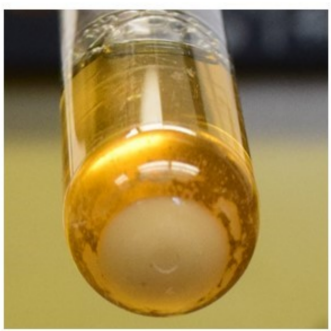

Figure 1. Morphology of Kazachstania slooffiae. K. slooffiae was grown for $24 \mathrm{~h}$ on Yeast Potato Dextrose Agar (YPD) (A) and Sabouraud Dextrose (SD) (C) agars. Individual colony morphology on YPD demonstrates concave growth (B) and SD demonstrated flat colony growth (D). Growth in $5 \mathrm{~mL}$ YPD broth (E,F).

A

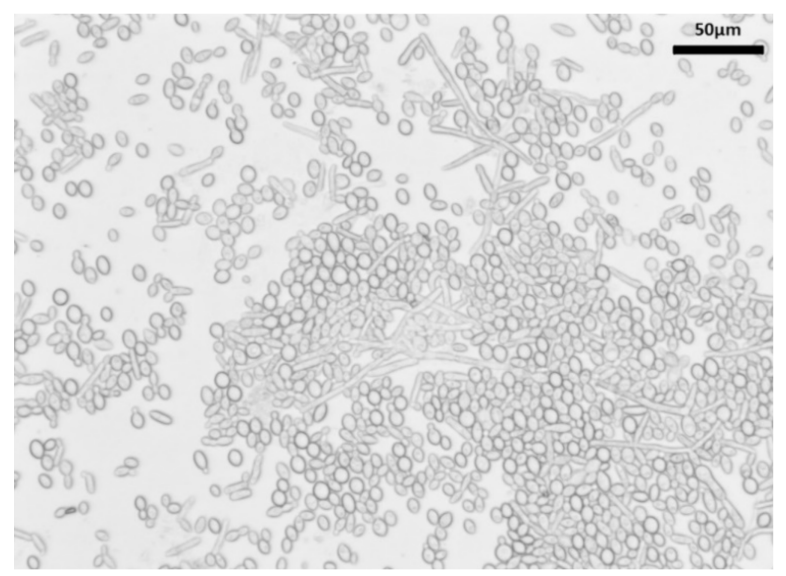

B

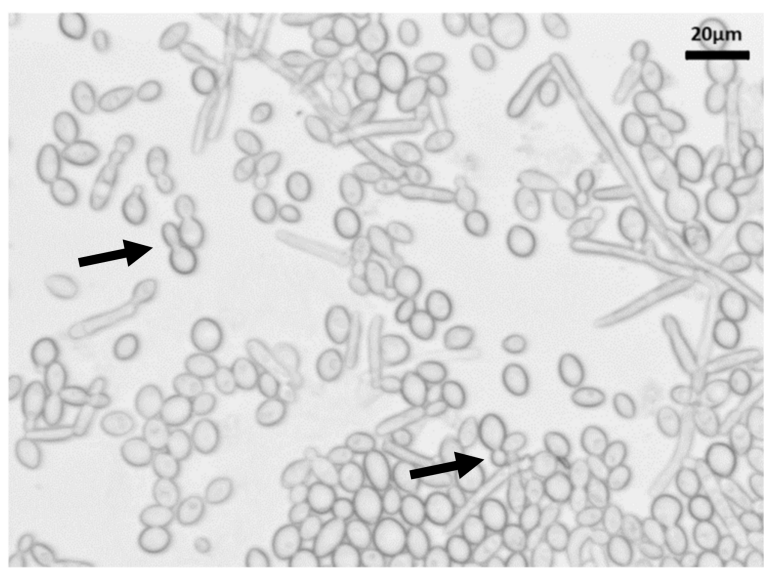

Figure 2. Microscopy of Kazachstania slooffiae. Polymorphic growth of K. slooffiae. K. slooffiae was grown in YPD + cef broth for $72 \mathrm{~h}$ and visualized by wet mount microscopy. (A) 20× objective displaying yeast and hyphal growth. (B) A mixed culture with multiple pseudohyphae seen and budding yeasts (arrows).

\section{Growth Curve}

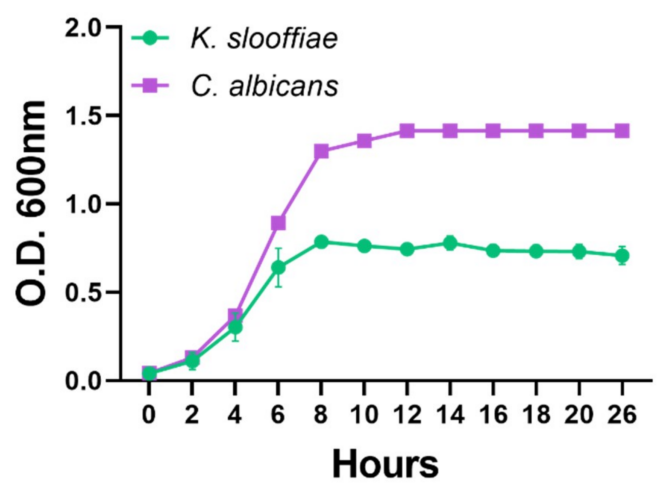

Figure 3. Growth curves of planktonic fungi. A) Kazachstania slooffiae (pig isolate, $n=26$ replicates) and Candida albicans CHN1 (human isolate, $n=9$ replicates). Data shown are the mean of replicates with error bars representing the standard deviation. 
Table 2. Antifungal susceptibility.

\begin{tabular}{cccc}
\hline Antimicrobial & Susceptible [Y/N] & $\begin{array}{c}\text { Antimicrobial } \\
\text { Concentration }\end{array}$ & Drug class \\
\hline Cefoperazone & $\mathrm{N}$ & $100 \mathrm{mg} / \mathrm{mL}$ & $\begin{array}{c}3^{\text {rd }} \text { generation } \\
\text { cephalosporin }\end{array}$ \\
\hline Ampicillin & $\mathrm{N}$ & $100 \mathrm{mg} / \mathrm{mL}$ & $\begin{array}{c}\text { Beta lactam } \\
\text { (penicillin) }\end{array}$ \\
\hline Caspofungin & $\mathrm{Y}$ & $0.094 \mathrm{ug} / \mathrm{mL}$ & Echinocandins \\
\hline Itraconazole & $\mathrm{Y}$ & $0.25 \mathrm{ug} / \mathrm{mL}$ & Azoles \\
\hline Voriconazole & $\mathrm{Y}$ & $0.023 \mathrm{ug} / \mathrm{mL}$ & Azoles \\
\hline Fluconazole & $\mathrm{Y}$ & $20 \mathrm{ug} / \mathrm{mL}$ & Azoles \\
\hline Amphotericin B & $\mathrm{Y}$ & $250 \mathrm{mg} / \mathrm{mL}$ & Polyenes \\
\hline Flucytosine & $\mathrm{Y}$ & $1.0 \mathrm{ug} / \mathrm{mL}$ & Pyrimidine analogue \\
\hline
\end{tabular}

Molecular studies. Whole DNA was isolated from K. slooffiae and C. albicans CHN1 and PCR amplification was performed for 18S, ITS-1, and ITS-2 fungal-specific primers sets that were previously published (Table 1). PCR amplicons were assessed by Agilent Bioanalyzer (Figure 4A) and confirmed on ethidium bromide gel (data not shown). Results are summarized to demonstrate expected amplicon size based on primer selection (Figure 4B). A total of $n=16$ full length ITS gene copies (ITS1-5.8S-ITS2) were extracted from the draft K. slooffiae genome and were confirmed as K. slooffiae, a member of the Kazachstania telluris complex, based on phylogenetic analysis (Figure 5). One gene identified with a length of 13,219 bp was removed from analysis due to being greater than the predicted size of the ITS gene region. Among these copies, $n=7$ non-identical ITS genes were detected at $>98.8 \%$ similarity, with lengths ranging from 719 to $721 \mathrm{bp}$ and divergence ranging from 1 to 8 nucleotides.

A.

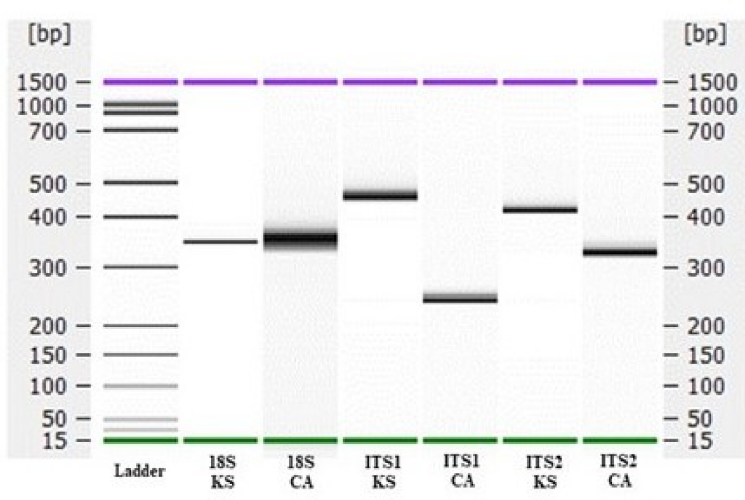

B.

\begin{tabular}{|cc}
\hline Sample & Amplicon Size (bp) \\
\hline 18S $\boldsymbol{K}$. slooffiae & 350 \\
\hline 18S C. albicans & 363 \\
ITS-1 K. slooffiae & 458 \\
ITS-1 C. albicans & 243 \\
ITS-2 K. slooffiae & 420 \\
\hline ITS-2 C. albicans & 329 \\
\hline
\end{tabular}

Figure 4. DNA amplicon size based on fungal-specific primer target. DNA isolated from K. slooffiae (KS) or C. albicans (CA) was amplified utilizing previously published primers (Table 1) for 18S, ITS-1, and ITS-2. Samples were run on an Agilent Bioanalyzer 2100; resulting amplicon sizes are shown by gel (A), and expected amplicon sizes are summarized (B).

Biofilm growth. Next, we assessed the ability of $K$. slooffiae to grow in a biofilm. While multiple medias and time points were assessed, $72 \mathrm{~h}$ and YPD + cef were found to be the optimum conditions for promoting K. slooffiae biofilms (data not shown). K. slooffiae was grown in YPD + cef broth, and serial dilutions of culture were added into each well of a 96-well tissue culture grade plate, wrapped with parafilm to prevent evaporation, and grown for $72 \mathrm{~h}$ and then assessed for biofilm formation by optical density reading at $595 \mathrm{~nm}$ (Figure 6). While biofilm growth showed a dilution trend at lower dilutions, starting culture above $10^{4}$ did not continue to become more optically dense, suggesting no further biofilm complexity. Bacterial supernatants from swine and human isolates were tested to examine if they could alter K. slooffiae biofilm complexity. Lactobacillus fermentum (human intestinal isolate) supernatant did not significantly alter K. slooffiae biofilms, while 
Lactobacillus acidophilus (swine intestinal isolate) supernatant significantly increased the optical density of the biofilms, suggesting an increase in biofilm complexity (Figure 6). Interestingly, the supernatant from a known opportunistic pathogen, Enterococcus faecalis (swine feces isolate) significantly inhibited K. slooffiae biofilm density, suggesting a potential antagonism.

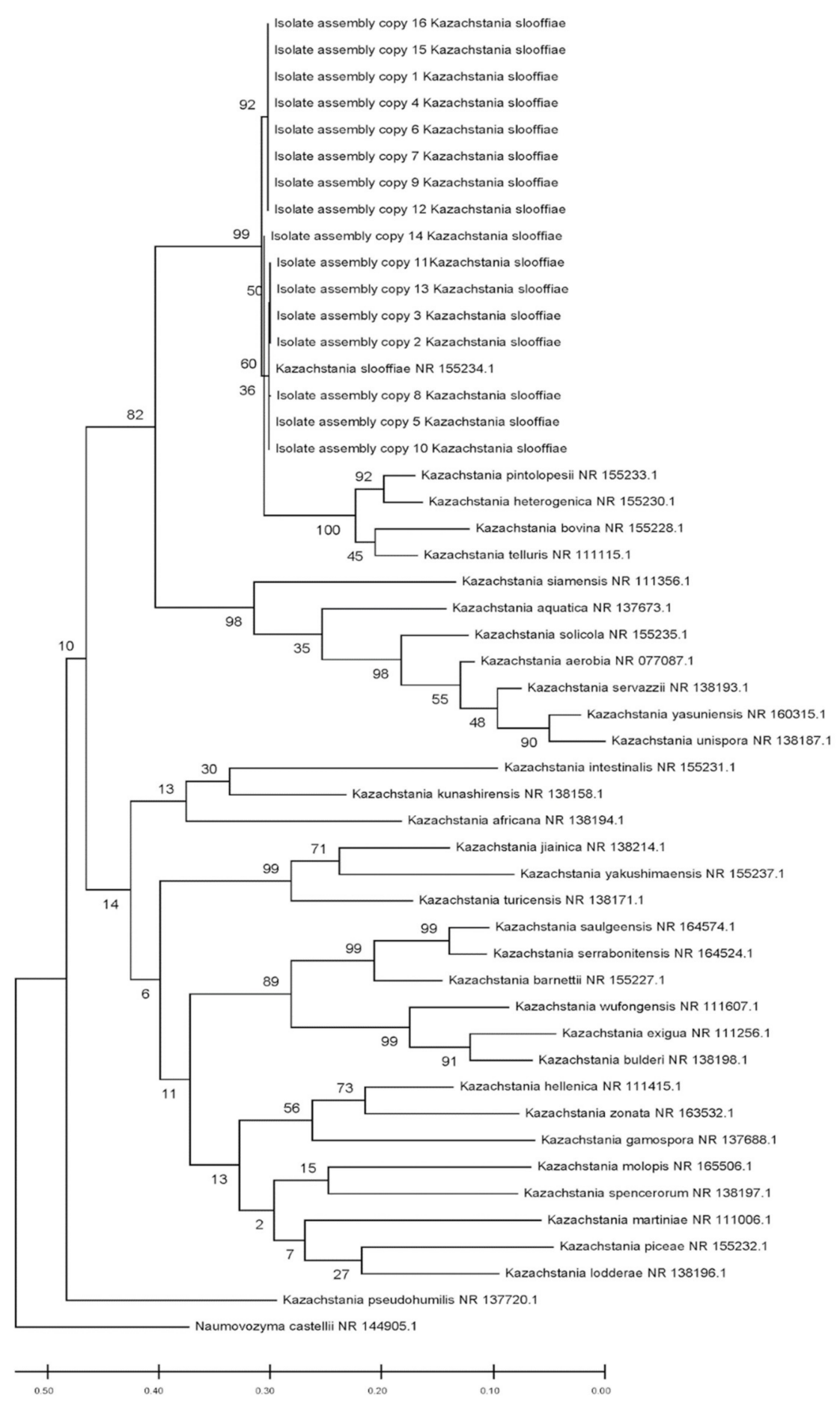

Figure 5. Phylogenetic tree of ITS gene (ITS1-5.8S-ITS2) sequences from Kazachstania sp. Accession numbers of reference species downloaded from the RefSeq database indicated at right of species name. K. slooffiae genes identified in this study indicated as 'Isolate assembly copy'. Maximum likelihood tree constructed using Tamura-Nei model and 1000 bootstrap replicates. Bootstrap values located above tree branches. Branch lengths measured in the number of substitutions per site. 


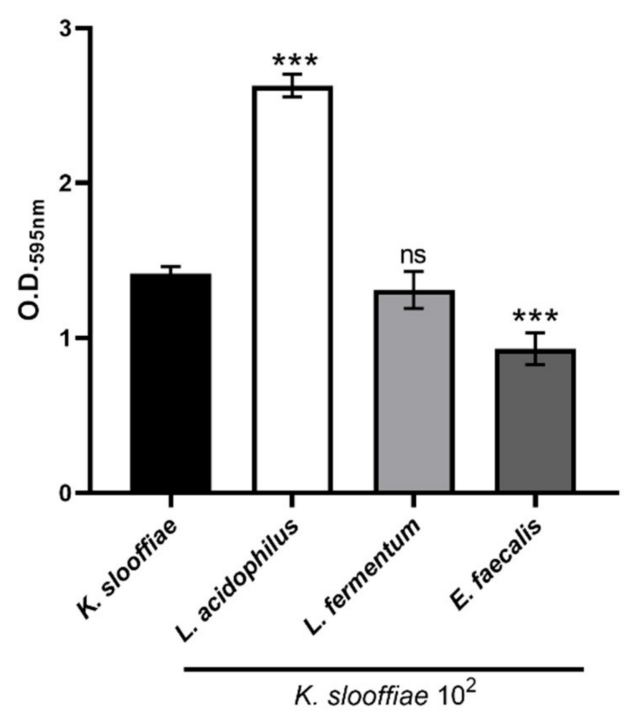

Figure 6. Biofilm assessment of $K$. slooffiae. K. slooffiae was grown in De Man, Rogosa, Sharpe broth (MRS) broth for $72 \mathrm{~h}$ without shaking at $37{ }^{\circ} \mathrm{C}$ and $5 \% \mathrm{CO}_{2}$. Following fixation, biofilms were stained with $0.4 \%$ crystal violet, washed, and O.D. readings were taken at $595 \mathrm{~nm}$. Bacterial supernatants were co-incubated with $K$. slooffiae biofilms to assess any alterations in the presence of Lactobacillus acidophilus, Lactobacillus fermentum, and Enterococcus faecalis. Data shown is three combined experiments of seven total experiments. ( $n=16$ to 64$)$. One-way ANOVA with a Tukey post-test was performed to determine significance. Error bars represent the standard deviation and *** represents $p<0.0001$ in comparison to K. slooffiae alone.

\section{Discussion}

Due to the potential importance of K. slooffiae in piglet health, we aimed to investigate optimal growth conditions, biofilm formation ability, expected DNA amplicons, and other in vitro assessments. K. slooffiae was able to efficiently grow on YPD or SD agars but displayed colony morphology alterations based on the nutrient base (Figure 1). Other fungal species have demonstrated convex or concave colony morphology patterns based on glucose availability [39], so we hypothesize that the morphology differences are due to sugar availability variances between the two agar types. Broth cultures of K. slooffiae displayed sedimentary growth regardless of incubation with or without shaking or growth in YPD or SDB (Figure 1E,F, data not shown).

Microscopy confirmed fungal growth as seen in previous work. K. slooffiae grows as a yeast and can produce pseudohyphae (Figure 2). A study by Kurtzman et al. demonstrated a single isolate of $K$. slooffiae that was able to form ascopores; however, no ascopores were seen in our isolate from piglet feces under any conditions [27]. It should be noted that the strain in the Kurtzman study required $15-20$ days of growth at $25^{\circ} \mathrm{C}$, and while this did not occur with our piglet-derived strain, it cannot be ruled out that this strain could potentially create ascopores under certain circumstances. Ascopores are spores formed within an ascus, a cylindrical-shaped sac, and they are specifically made by members of the Ascomycota. As with other types of spores, ascopores are utilized for survival and dispersion [40], and other Kazachstania species have been found to form ascopores [41]. Ascopores formed by other fungal species have demonstrated their contribution to virulence, especially in causing diseases of plants [42-44], but they have also been found to assist in survival through the gastrointestinal tract of Drosophila [45]. Other microbes rely on sporulation to survive gut conditions [46]; therefore, ascopore formation cannot be ruled out as an important factor for K. slooffiae. The role of ascopores in piglet gut survival for K. slooffiae is unknown, but future studies must be done to ascertain how many strains of $K$. slooffiae form ascopores and under which conditions, as they may play an important role in the survival and transmission in piglets. 
In order to assess the growth of $K$. slooffiae, we performed growth curve analyses. For comparison, we concurrently analyzed the human gut fungal isolate, C. albicans CHN1. Similar to K. slooffiae, C. albicans is a polymorphic yeast found in healthy GI tracts and feces [47], but while $C$. albicans is a commensal, it is also a well-documented opportunistic pathogen. We propose that $K$. slooffiae is a gut commensal in pigs, but currently, little is known about the potential virulence of $K$. slooffiae. Our growth curves demonstrate that under laboratory conditions, $C$. albicans is able to grow to a significantly higher density in YPD or SDB than K. slooffiae (Figure 3 and data not shown). While this rapid fungal growth may be specific to the laboratory setting, it could also demonstrate the ability of $C$. albicans to grow rapidly in the GI setting, promoting its commensalism through interactions with the gut microbiome and host immune response. However, $C$. albicans could also utilize this rapid growth to assist its opportunistic pathogenicity. K. slooffiae grows slower under all tested laboratory conditions, but the implications of this comparatively reduced growth in vivo remain to be assessed. In vivo growth conditions may be more optimal to promote faster growth for K. slooffiae, or perhaps its slow growth is retained in vivo and plays a role in immune recognition not resulting in clearance. Future work necessitates the sequencing of the K. slooffiae genome to provide genetic comparisons to elucidate any potential virulence factors utilized by fungal pathogens, such as adhesins, dimorphism, phospholipases, and aspartyl proteases [48,49].

Fungal identification alone is not sufficient when investigating complex environments such as the porcine gut. Further, fungal-specific primers have been documented to miss certain species entirely. To assess the ability of fungal-specific primers to amplify the DNA from K. slooffiae, we isolated whole DNA and performed PCR amplification with three different previously published primer sets (Figure 4A). Primers for 18S, ITS-1, and ITS-2 were all able to efficiently amplify these target sequences in $K$. slooffiae, and the resulting amplicon sizes are documented here (Figure 4B). A caveat of these results is that the DNA was isolated from a homogenous culture and not from heterogenous sample such as feces or luminal contents, simplifying fungal amplification. Despite the simplicity of the amplification, these data are important when assessing $K$. slooffiae in the context of the piglet gut and feces, as different fungal primer sets can have different efficiencies based on the environmental sample being assessed. These data establish accurate expected amplicons to help identify this fungus in the future. We have previously published work suggesting that ITS-2 specific primers are the appropriate choice for piglet gut and fecal samples [21], but we also suggest a combinatorial approach when studying a new sample set, utilizing more than one fungal-specific primer set [50].

In addition to targeted amplification, we also examined the complete ITS gene region from our K. slooffiae isolate and then extracted an assembled draft genome of our isolate based on whole genome shotgun sequencing. This allowed for a full-length ITS phylogenetic identification and comparison of $K$. slooffiae, as well as the determination of potential repetitive ITS regions and heterozygosity. Since there is currently no available published genome of K. slooffiae and the heterozygosity and polyploidism of this species is unknown, a complete assembly of this genome remains a challenge. Based on our draft assembly, 16 copies of the ITS gene were detected with seven different copy variations and were identified as K. slooffiae within the Kazachstania telluris complex. While some of these copies may be a result of potential sequencing errors and unresolved consensus sequences, ITS repeats in the genome may also be due to multiple copies of rDNA present in many fungal species. In fungi, rDNA copies are estimated to range from 14 to 1422 copies [51] and may vary due to environmental conditions [52]. Furthermore, the variation found in the K. slooffiae ITS copies may result from heterozygosity or polyploidism, which is known to be prevalent in many types of fungi [53,54]. Additional analysis including the qPCR of rDNA copy numbers and newer sequencing technology such as Hi-Fi [55] will provide further insight into the K. slooffiae genome.

While fungi have recently gained interest in the medical field due to their drug resistance, such as Candida auris, our studies suggest that $K$. slooffiae does not currently 
possess significant drug resistance (Table 2) [56]. Our current data do not suggest that K. slooffiae behaves as an opportunistic pathogen, but that cannot be ruled out. Resistance to polyenes, pyrimidine analogues, azoles, and echinocandins have been seen in similar fungi, such as $C$. albicans, and these resistances were often due to simple mutations in one to two genes [57]. C. auris has been found to be highly drug resistant, which is a critical health concern due to a lack in novel antifungal drugs [58]. Recently, fluconazole resistance was seen in uncommon yeast pathogens, including Kazachstania telluris, Kazachstania bovina, Kazachstania exigua, and Kazachstania servazzii [59]. The ability of $K$. slooffiae to become drug resistant remains to be elucidated, but due to the rarity of Kazachstania sp. becoming antifungal or multi-drug resistant, it seems unlikely that resistance will become a problem.

We performed preliminary experiments to assess the ability of $K$. slooffiae to form biofilms. Similar to the susceptibility testing of fungi to antifungals, experiments were carried out to identify major inhibitory effects. Utilizing previously described biofilm protocols, we assessed growth conditions including time of growth, fixation method utilized, and nutrient conditions used [37,38]. After optimizing conditions, we assessed a dilution series of $K$. slooffiae to determine if the starting culture density affected biofilm development. Unexpectedly, we found that higher density starting cultures did not create more optically dense biofilms. In fact, a lesser range of $10^{2}-10^{4}$ was found to be optimal when starting biofilms, suggesting quorum sensing involvement in optimal biofilm growth (data not shown). Next, we assessed the ability of gut bacterial supernatants to alter K. slooffiae biofilm formation. Previous studies have found the ability of bacterial supernatants to alter bacterial and fungal biofilm growth [60-62], and our inferred interactions suggest this may be occurring in the piglet gut. We found that while L. acidophilus supernatant was able to enhance biofilm formation, L. fermentum did not significantly alter biofilm density. Supernatant from a strain of $E$. faecalis isolated from piglet feces significantly decreased the optical density of $K$. slooffiae biofilms, suggesting an antagonism. While the composition of the supernatant remains to be determined, cross-species quorum-sensing molecules or secreted molecules such as capsules could play a role $[63,64]$. Future studies will assess the biofilm composition through microscopy and will determine the composition of the bacterial and fungal supernatants for quorum sensing molecules or other molecules of interest. Studies will be done to assess the role of supernatant acidities and the effect of $\mathrm{pH}$ on biofilm density and formation. One other factor of interest is the role of ethanol production as a bacterial product that plays a role in impeding biofilm growth and will need to be investigated further [65]. Furthermore, differences in supernatant effects on planktonic versus biofilm $K$. slooffiae are of interest to determine the quorum-sensing molecules utilized by this fungus.

The weaning transition is a critical period in a piglet's life when piglets are removed from their mothers, placed into new housing pens, and started on solid diet. These significant changes are associated with a dramatic shift in microbial communities, including the mycobiome. Previous studies have demonstrated conflicting data on which porcine gut organs harbor the most K. slooffiae $[19,21,25,64]$, but overall, K. slooffiae has been found to become the predominant fungal species found in the feces and gut organs of healthy, post-weaning pigs. However, details on its growth or interactions with the bacteriome are lacking. Previous inferred interactions have suggested that $K$. slooffiae has positive interactions with beneficial bacteria such as Prevotella $[19,20]$. K. slooffiae was previously assessed for its ability to utilize organic acids and amino acids as carbon and energy sources [22], and this fungus was not able to utilize lactic, butyric, proprionic, or acetic acid as a sole carbon source in vitro; however, this ability in the gut environment cannot be ruled out [22]. Further, Urubschurov et al. found that K. slooffiae does not use free lysine as a sole nitrogen source, eliminating this as a potential competition with the host. These authors hypothesized that one way that $K$. slooffiae could benefit the host was through the ability to form dehydroascorbic acid, which could be beneficial for animals. K. slooffiae is able to utilize glucose but has not been documented as utilizing galactose [22,26,27]. They hypothesized that $K$. slooffiae may be a protein source to piglets. This underscores 
the fact that pre-weanling piglets, that only ingest milk, do not have significant K. slooffiae populations, which is perhaps due to an inability to utilize the galactose in lactose. Glucose consumption is also seen in the bacterial species tested in biofilms, and while L. acidophilus continues to produce glucose over multiple days, glucose production by L. fermentum is reduced after $48 \mathrm{~h}$, which may be a factor limiting fungal growth in the mixed biofilm [65].

Due to the potential for important interactions in the porcine GI tract, more work must be done to determine bacterial-fungal-host interactions that can alter piglet growth performance. One previous study fed K. slooffiae to piglets approximately one-week postweaning, and no direct growth performance changes were seen [22] but gut colonization was seen with only one feeding supplementation. Despite this sole study, inferred interactions suggest that beneficial bacteria and $K$. slooffiae may be having positive interactions. Positive biofilm interactions between $K$. slooffiae and L. acidophilus support the potential for interactions in the gut setting. Equally interesting are the negative interactions seen in the biofilm studies involving E. faecalis; investigations elucidating the potential for microbial inhibition in the gut setting remain of interest. Furthermore, supplementation leading up to weaning has not been assessed in vivo and may help in preventing post-weaning opportunistic diseases and piglet weight loss. Previous studies have found that many of the fungal species found in the gut were transient due to their nutritional and environmental needs. It is possible that much of the piglet mycobiome is made up of transient fungi introduced in the feed and other environmental factors. However, the mycobiome is also able to alter health and is more easily altered than the bacteriome, creating the potential for an effective piglet health intervention strategy. In this study, we provided comprehensive growth parameters for $K$. slooffiae in vitro and the effects of gut and fecal bacterial samples on biofilm development and density. Further explorations in the piglet and laboratory setting will provide a greater understanding of the complex interactions occurring in the piglet gut milieu that can lead to alterations in piglet growth and health.

Author Contributions: K.L.S. designed and performed experiments and composed the manuscript, A.M.A. performed genomic analyses, created figures for publication, and edited the manuscript, J.F.F. performed experiments and edited the manuscript. All authors have read and agreed to the published version of the manuscript.

Funding: No external funding was used in this study.

Institutional Review Board Statement: The animal study was reviewed and approved by the USDAARS Institutional Animal Care and Use Committee of the Beltsville Agricultural Research Center.

Informed Consent Statement: Not applicable.

Data Availability Statement: The datasets generated for this study can be found using the Accession number SUB9028074, https: / / submit.ncbi.nlm.nih.gov/subs/genbank/SUB9028074 / (accessed on 16 February 2021).

Acknowledgments: We would like to kindly thank the Huffnagle laboratory at the University of Michigan for providing the culture of Candida albicans CHN1 and Nicole Falkowski for her assistance in this process.

Conflicts of Interest: The authors declare that the research was conducted in the absence of any commercial or financial relationships that could be construed as a potential conflict of interest. We would also like to thank the Veterinary Animal Services at the Beltsville Agricultural Research Center for support with our animal studies.

\section{References}

1. Campbell, J.M.; Crenshaw, J.D.; Polo, J. The biological stress of early weaned piglets. J. Anim. Sci. Biotechnol. 2013, 4, 19. [CrossRef]

2. Guevarra, R.B.; Hong, S.H.; Cho, J.H.; Kim, B.R.; Shin, J.; Lee, J.H.; Kang, B.N.; Kim, Y.H.; Wattanaphansak, S.; Isaacson, R.E.; et al. The dynamics of the piglet gut microbiome during the weaning transition in association with health and nutrition. J. Anim. Sci. Biotechnol. 2018, 9, 54. [CrossRef] [PubMed]

3. Guevarra, R.B.; Lee, J.H.; Lee, S.H.; Seok, M.J.; Kim, D.W.; Kang, B.N.; Johnson, T.J.; Isaacson, R.E.; Kim, H.B. Piglet gut microbial shifts early in life: Causes and effects. J. Anim. Sci. Biotechnol. 2019, 10, 1. [CrossRef] 
4. Huffnagle, G.B.; Noverr, M.C. The emerging world of the fungal microbiome. Trends Microbiol. 2013, 21, 334-341. [CrossRef] [PubMed]

5. Ott, S.J.; Kuhbacher, T.; Musfeldt, M.; Rosenstiel, P.; Hellmig, S.; Rehman, A.; Drews, O.; Weichert, W.; Timmis, K.N.; Schreiber, S. Fungi and inflammatory bowel diseases: Alterations of composition and diversity. Scand. J. Gastroenterol. $2008,43,831-841$. [CrossRef] [PubMed]

6. Iliev, I.D.; Funari, V.A.; Taylor, K.D.; Nguyen, Q.; Reyes, C.N.; Strom, S.P.; Brown, J.; Becker, C.A.; Fleshner, P.R.; Dubinsky, M.; et al. Interactions between commensal fungi and the C-type lectin receptor Dectin-1 influence colitis. Science 2012, 336, 1314-1317. [CrossRef] [PubMed]

7. Mason, K.L.; Erb Downward, J.R.; Falkowski, N.R.; Young, V.B.; Kao, J.Y.; Huffnagle, G.B. Interplay between the gastric bacterial microbiota and Candida albicans during postantibiotic recolonization and gastritis. Infect. Immun. 2012, 80, 150-158. [CrossRef]

8. Erb Downward, J.R.; Falkowski, N.R.; Mason, K.L.; Muraglia, R.; Huffnagle, G.B. Modulation of post-antibiotic bacterial community reassembly and host response by Candida albicans. Sci. Rep. 2013, 3, 2191. [CrossRef]

9. Li, Q.; Wang, C.; Tang, C.; He, Q.; Li, N.; Li, J. Dysbiosis of gut fungal microbiota is associated with mucosal inflammation in Crohn's disease. J. Clin. Gastroenterol. 2014, 48, 513-523. [CrossRef] [PubMed]

10. Liu, Y.; Zheng, Z.; Yu, L.; Wu, S.; Sun, L.; Wu, S.; Xu, Q.; Cai, S.; Qin, N.; Bao, W. Examination of the temporal and spatial dynamics of the gut microbiome in newborn piglets reveals distinct microbial communities in six intestinal segments. Sci. Rep. 2019, 9, 3453. [CrossRef]

11. Frey-Klett, P.; Burlinson, P.; Deveau, A.; Barret, M.; Tarkka, M.; Sarniguet, A. Bacterial-fungal interactions: Hyphens between agricultural, clinical, environmental, and food microbiologists. Microbiol. Mol. Biol. Rev. 2011, 75, 583-609. [CrossRef] [PubMed]

12. Suhr, M.J.; Hallen-Adams, H.E. The human gut mycobiome: Pitfalls and potentials-A mycologist's perspective. Mycologia 2015, 107, 1057-1073. [CrossRef]

13. Mukherjee, P.K.; Sendid, B.; Hoarau, G.; Colombel, J.F.; Poulain, D.; Ghannoum, M.A. Mycobiota in gastrointestinal diseases. Nat. Rev. Gastroenterol Hepatol. 2015, 12, 77-87. [CrossRef]

14. Kureljusic, B.; Weissenbacher-Lang, C.; Nedorost, N.; Stixenberger, D.; Weissenbock, H. Association between Pneumocystis spp. and co-infections with Bordetella bronchiseptica, Mycoplasma hyopneumoniae and Pasteurella multocida in Austrian pigs with pneumonia. Vet. J. 2016, 207, 177-179. [CrossRef]

15. Weissenbacher-Lang, C.; Kureljusic, B.; Nedorost, N.; Matula, B.; Schiessl, W.; Stixenberger, D.; Weissenbock, H. Retrospective Analysis of Bacterial and Viral Co-Infections in Pneumocystis spp. Positive Lung Samples of Austrian Pigs with Pneumonia. PLoS ONE 2016, 11, e0158479. [CrossRef] [PubMed]

16. Iliev, I.D.; Leonardi, I. Fungal dysbiosis: Immunity and interactions at mucosal barriers. Nat. Rev. Immunol. 2017, 17, 635-646. [CrossRef]

17. Limon, J.J.; Skalski, J.H.; Underhill, D.M. Commensal Fungi in Health and Disease. Cell Host Microbe. 2017, 22, 156-165. [CrossRef]

18. Richard, M.L.; Sokol, H. The gut mycobiota: Insights into analysis, environmental interactions and role in gastrointestinal diseases. Nat. Rev. Gastroenterol. Hepatol. 2019, 16, 331-345. [CrossRef] [PubMed]

19. Arfken, A.M.; Frey, J.F.; Ramsay, T.G.; Summers, K.L. Yeasts of Burden: Exploring the Mycobiome-Bacteriome of the Piglet GI Tract. Front. Microbiol. 2019, 10, 2286. [CrossRef]

20. Arfken, A.M.; Frey, J.F.; Summers, K.L. Temporal Dynamics of the Gut Bacteriome and Mycobiome in the Weanling Pig. Microorganisms 2020, 8, 868. [CrossRef]

21. Summers, K.L.; Frey, J.F.; Ramsay, T.G.; Arfken, A.M. The piglet mycobiome during the weaning transition: A pilot study. J. Anim. Sci. 2019, 97, 2889-2900. [CrossRef] [PubMed]

22. Urubschurov, V.; Busing, K.; Freyer, G.; Herlemann, D.P.; Souffrant, W.B.; Zeyner, A. New insights into the role of the porcine intestinal yeast, Kazachstania slooffiae, in intestinal environment of weaned piglets. FEMS Microbiol. Ecol. 2017, 93. [CrossRef]

23. Urubschurov, V.; Busing, K.; Janczyk, P.; Souffrant, W.B.; Zeyner, A. Development and Evaluation of qPCR Assay for Quantitation of Kazachstania slooffiae and Total Yeasts Occurring in the Porcine Gut. Curr. Microbiol. 2015, 71, 373-381. [CrossRef] [PubMed]

24. Urubschurov, V.; Busing, K.; Souffrant, W.B.; Schauer, N.; Zeyner, A. Porcine intestinal yeast species, Kazachstania slooffiae, a new potential protein source with favourable amino acid composition for animals. J. Anim. Physiol. Anim. Nutr. (Berl) 2018, 102, e892-e901. [CrossRef]

25. Urubschurov, V.; Janczyk, P.; Pieper, R.; Souffrant, W.B. Biological diversity of yeasts in the gastrointestinal tract of weaned piglets kept under different farm conditions. FEMS Yeast Res. 2008, 8, 1349-1356. [CrossRef]

26. Urubschurov, V.; Janczyk, P.; Souffrant, W.B.; Freyer, G.; Zeyner, A. Establishment of intestinal microbiota with focus on yeasts of unweaned and weaned piglets kept under different farm conditions. FEMS Microbiol. Ecol. 2011, 77, 493-502. [CrossRef]

27. Kurtzman, C.P.; Robnett, C.J.; Ward, J.M.; Brayton, C.; Gorelick, P.; Walsh, T.J. Multigene phylogenetic analysis of pathogenic candida species in the Kazachstania (Arxiozyma) telluris complex and description of their ascosporic states as Kazachstania bovina sp. nov., K. heterogenica sp. nov., K. pintolopesii sp. nov., and K. slooffiae sp. nov. J. Clin. Microbiol. 2005, 43, 101-111. [PubMed]

28. White, T.J.; Burns, T.; Lee, S.; Taylor, J. Amplification and sequencing of fungal ribosomal RNA genes for phylogenetics. In PCR Protocols: A Guide to Methods and Applications; Innis, M.A., Gelfand, D.H., Sninsky, J.J., White, T.J., Eds.; Academic Press: San Diego, CA, USA, 1990; pp. 315-322. 
29. Chin, C.S.; Peluso, P.; Sedlazeck, F.J.; Nattestad, M.; Concepcion, G.T.; Clum, A.; Dunn, C.; O’Malley, R.; Figueroa-Balderas, R.; Morales-Cruz, A.; et al. Phased diploid genome assembly with single-molecule real-time sequencing. Nat. Methods 2016, 13, 1050-1054. [CrossRef]

30. Usyk, M.; Zolnik, C.P.; Patel, H.; Levi, M.H.; Burk, R.D. Novel ITS1 Fungal Primers for Characterization of the Mycobiome. mSphere 2017, 2. [CrossRef]

31. Vainio, E.J.; Hantulo, J. Direct analysis of wood-inhabiting fungi using denaturing gradient gel electrophoresis of amplified ribosomal DNA. Mycol. Res. 2000, 104, 927-936. [CrossRef]

32. Bengtsson-Palme, J.; Ryberg, M.; Hartmann, M.; Branco, S.; Wang, Z.; Godhe, A.; De Wit, P.; Sanchez-Garcia, M.; Ebersberger, I.; de Sousa, F.; et al. Improved software detection and extraction of ITS1 and ITS2 from ribosomal ITS sequences of fungi and other eukaryotes for analysis of environmental sequencing data. Methods Ecol. Evol. 2013. [CrossRef]

33. O'Leary, N.A.; Wright, M.W.; Brister, J.R.; Ciufo, S.; Haddad, D.; McVeigh, R.; Rajput, B.; Robbertse, B.; Smith-White, B.; Ako-Adjei, D.; et al. Reference sequence (RefSeq) database at NCBI: Current status, taxonomic expansion, and functional annotation. Nucleic Acids Res. 2016, 44, D733-D745. [CrossRef]

34. Edgar, R.C. MUSCLE: Multiple sequence alignment with high accuracy and high throughput. Nucleic Acids Res. 2004, 32, 1792-1797. [CrossRef] [PubMed]

35. Tamura, K.; Nei, M. Estimation of the number of nucleotide substitutions in the control region of mitochondrial DNA in humans and chimpanzees. Mol. Biol. Evol. 1993, 10, 512-526.

36. Kumar, S.; Stecher, G.; Li, M.; Knyaz, C.; Tamura, K. MEGA X: Molecular Evolutionary Genetics Analysis across Computing Platforms. Mol. Biol. Evol. 2018, 35, 1547-1549. [CrossRef] [PubMed]

37. Dassanayake, R.P.; Falkenberg, S.M.; Stasko, J.A.; Shircliff, A.L.; Lippolis, J.D.; Briggs, R.E. Identification of a reliable fixative solution to preserve the complex architecture of bacterial biofilms for scanning electron microscopy evaluation. PLoS ONE 2020, 15, e0233973. [CrossRef] [PubMed]

38. Haney, E.F.; Mansour, S.C.; Hilchie, A.L.; de la Fuente-Nunez, C.; Hancock, R.E. High throughput screening methods for assessing antibiofilm and immunomodulatory activities of synthetic peptides. Peptides 2015, 71, 276-285. [CrossRef] [PubMed]

39. Chen, L.; Noorbakhsh, J.; Adams, R.M.; Samaniego-Evans, J.; Agollah, G.; Nevozhay, D.; Kuzdzal-Fick, J.; Mehta, P.; Balazsi, G Two-dimensionality of yeast colony expansion accompanied by pattern formation. Plos Comput. Biol. 2014, 10, e1003979. [CrossRef] [PubMed]

40. Neiman, A.M. Ascospore formation in the yeast Saccharomyces cerevisiae. Microbiol Mol. Biol Rev. 2005, 69, 565-584. [CrossRef]

41. Imanishi, Y.; Ueda-Nishimura, K.; Mikata, K. Two new species of Kazachstania that form ascospores connected by a belt-like intersporal body: Kazachstania zonata and Kazachstania gamospora. FEMS Yeast Res. 2007, 7, 330-338. [CrossRef]

42. Tran, N.T.; Miles, A.K.; Smith, M.W.; Dietzgen, R.G.; Drenth, A. Pathogenicity of Phyllosticta citricarpa Ascospores on Citrus spp. Plant. Dis. 2018, 102, 1386-1393. [CrossRef]

43. Njambere, E.N.; Chen, W.; Frate, C.; Temple, S.R. Ascospore dimorphism-associated mating types of Sclerotinia trifoliorum equally capable of inducing mycelial infection on chickpea plants. Australas. Plant. Pathol. 2011, 40, 648-655. [CrossRef]

44. Trail, F. Fungal cannons: Explosive spore discharge in the Ascomycota. Fems Microbiol Lett 2007, 276, 12-18. [CrossRef] [PubMed]

45. Coluccio, A.E.; Rodriguez, R.K.; Kernan, M.J.; Neiman, A.M. The yeast spore wall enables spores to survive passage through the digestive tract of Drosophila. PLoS ONE 2008, 3, e2873. [CrossRef]

46. Wilcks, A.; Hansen, B.M.; Hendriksen, N.B.; Licht, T.R. Fate and effect of ingested Bacillus cereus spores and vegetative cells in the intestinal tract of human-flora-associated rats. FEMS Immunol. Med. Microbiol. 2006, 46, 70-77. [CrossRef]

47. Neville, B.A.; d'Enfert, C.; Bougnoux, M.E. Candida albicans commensalism in the gastrointestinal tract. FEMS Yeast Res. 2015, 15.

48. Calderone, R.A.; Fonzi, W.A. Virulence factors of Candida albicans. Trends Microbiol. 2001, 9, 327-335. [CrossRef]

49. Mayer, F.L.; Wilson, D.; Hube, B. Candida albicans pathogenicity mechanisms. Virulence 2013, 4, 119-128. [CrossRef]

50. Summers, K.L.; Arfken, A.M. The Gut Mycobiome and Animal Health; Springer: Berlin, Germany, 2021.

51. Lofgren, L.A.; Uehling, J.K.; Branco, S.; Bruns, T.D.; Martin, F.; Kennedy, P.G. Genome-based estimates of fungal rDNA copy number variation across phylogenetic scales and ecological lifestyles. Mol. Ecol. 2019, 28, 721-730. [CrossRef] [PubMed]

52. Lavrinienko, A.; Jernfors, T.; Koskimaki, J.J.; Pirttila, A.M.; Watts, P.C. Does Intraspecific Variation in rDNA Copy Number Affect Analysis of Microbial Communities? Trends Microbiol. 2021, 29, 19-27. [CrossRef]

53. Todd, R.T.; Forche, A.; Selmecki, A. Ploidy Variation in Fungi: Polyploidy, Aneuploidy, and Genome Evolution. Microbiol. Spectr. 2017, 5 .

54. Galagan, J.E.; Henn, M.R.; Ma, L.J.; Cuomo, C.A.; Birren, B. Genomics of the fungal kingdom: Insights into eukaryotic biology. Genome Res. 2005, 15, 1620-1631. [CrossRef]

55. Wenger, A.M.; Peluso, P.; Rowell, W.J.; Chang, P.C.; Hall, R.J.; Concepcion, G.T.; Ebler, J.; Fungtammasan, A.; Kolesnikov, A.; Olson, N.D.; et al. Accurate circular consensus long-read sequencing improves variant detection and assembly of a human genome. Nat. Biotechnol. 2019, 37, 1155-1162. [CrossRef]

56. Jeffery-Smith, A.; Taori, S.K.; Schelenz, S.; Jeffery, K.; Johnson, E.M.; Borman, A.; Candida auris Incident Management Team; Manuel, R.; Brown, C.S. Candida auris: A Review of the Literature. Clin. Microbiol. Rev. 2018, 31. [CrossRef] [PubMed]

57. Costa-de-Oliveira, S.; Rodrigues, A.G. Candida albicans Antifungal Resistance and Tolerance in Bloodstream Infections: The Triad Yeast-Host-Antifungal. Microorganisms 2020, 8, 154. [CrossRef] 
58. Lockhart, S.R.; Berkow, E.L.; Chow, N.; Welsh, R.M. Candida auris for the clinical microbiology laboratory: Not your grandfather's Candida species. Clin. Microbiol. Newsl. 2017, 39, 99-103. [CrossRef] [PubMed]

59. Borman, A.M.; Muller, J.; Walsh-Quantick, J.; Szekely, A.; Patterson, Z.; Palmer, M.D.; Fraser, M.; Johnson, E.M. Fluconazole Resistance in Isolates of Uncommon Pathogenic Yeast Species from the United Kingdom. Antimicrob. Agents Chemother. 2019, 63. [CrossRef] [PubMed]

60. Tan, Y.; Leonhard, M.; Moser, D.; Schneider-Stickler, B. Inhibition activity of Lactobacilli supernatant against fungal-bacterial multispecies biofilms on silicone. Microb. Pathog. 2017, 113, 197-201. [CrossRef]

61. Maslennikova, I.L.; Kuznetsova, M.V.; Nekrasova, I.V.; Shirshev, S.V. Effect of bacterial components of mixed culture supernatants of planktonic and biofilm Pseudomonas aeruginosa with commensal Escherichia coli on the neutrophil response in vitro. Pathog. Dis. 2017, 75. [CrossRef] [PubMed]

62. Frickmann, H.; Klenk, C.; Warnke, P.; Redanz, S.; Podbielski, A. Influence of Probiotic Culture Supernatants on In Vitro Biofilm Formation of Staphylococci. Eur. J. Microbiol. Immunol. (Bp) 2018, 8, 119-127. [CrossRef]

63. Tarkka, M.T.; Sarniguet, A.; Frey-Klett, P. Inter-kingdom encounters: Recent advances in molecular bacterium-fungus interactions. Curr. Genet. 2009, 55, 233-243. [CrossRef] [PubMed]

64. Valle, J.; Da Re, S.; Henry, N.; Fontaine, T.; Balestrino, D.; Latour-Lambert, P.; Ghigo, J.M. Broad-spectrum biofilm inhibition by a secreted bacterial polysaccharide. Proc. Natl. Acad. Sci. USA 2006, 103, 12558-12563. [CrossRef] [PubMed]

65. Charalampopoulos, D.; Pandiella, S.S.; Webb, C. Growth studies of potentially probiotic lactic acid bacteria in cereal-based substrates. J. Appl. Microbiol. 2002, 92, 851-859. [CrossRef] [PubMed] 